\title{
Espectros vagantes: o Vertigem, a rua e o inferno do trabalho
}

É fato que toda obra é indissociável do onde e do quando é produzida. Mas há certos artistas para quem estes laços têm um papel fundamental. É impossível compreender a natureza da criação do Teatro da Vertigem sem ter como centro esta relação entre o teatro e a cidade que o cerca. Suas formas de criar e interagir com a metrópole são mais que uma condição intransponível; são uma reivindicação, um grito, um desejo essencial destes artistas. Sua arte é uma resposta a um estado de coisas.

No caso de "Bom Retiro, 958 Metros", é transposta uma fronteira fundamental na trajetória do coletivo: é a primeira vez que o grupo foi para a rua. Embora experiências anteriores tenham promovido radicais intervenções na cidade, nunca o Vertigem havia partido para este tipo de criação. Assim o diretor Antônio Araújo avalia o fato de ir para o espaço público totalmente aberto:

A rua tem um dado muito dispersivo. Isso nos coloca um problema, que é: de que forma que você consegue não resolver a dispersão, mas sim tensionála? Como é que você, com a cena, o corpo, o texto, a voz, a luz... Como é que você consegue estabelecer uma queda de braço com esse espaço que é aberto a tudo? Eu gosto de uma ideia de luta, porque em uma luta você ganha e perde. E ao longo do trabalho isso acontece. Tem dias que a rua é mais forte. Tem dias que somos nós; conseguimos nos inscrever mais. Há esse risco por ser algo aberto, sempre à beira do inesperado, há coisas que você não consegue prever, imaginar, e isso é um dado com o qual lidamos. Mas isso foi um aprendizado. No Tietê [quando o grupo encenou BR-3 no Rio Tietê, em 2006] nós já tínhamos ido para um espaço aberto. E aí tinha pessoas que gritavam, que de cima da ponte jogavam coisas nos atores... O ambiente era aberto, mas havia uma circunscrição feita pelo rio. Aqui, não. O grupo nunca tinha se exposto, se escancarado dessa forma.

Para compreender a natureza deste movimento, é revelador olhar para o nascimento do espetáculo. A relação de alguns dos integrantes do grupo com o bairro já vem de muitos anos. Roberto Audio, Antônio Araújo e Guilherme Bonfanti trabalharam no projeto Didática da Encenação, na Oficina Cultural Três Rios, hoje Oficina Cultural

\footnotetext{
${ }^{1}$ É jornalista, repórter do jornal O Estado de S. Paulo e mestrando da FFLCH-USP
} 
Oswald de Andrade, nos anos 1990, e apontam esta experiência como marcante em suas vidas. Em 1999, o grupo seria invadido mais fortemente em âmbito coletivo por esta presença no bairro ao longo do processo de criação de "Apocalipse 1, 11" (que estreou em janeiro de 2000), todo ensaiado na Oswald. Na observação de Araújo:

\begin{abstract}
Acho que essa conexão com o bairro surgiu nesse momento. Porque é algo que entra. Você está lá todos os dias, por várias horas, não há como não ser atravessado pela experiência de estar ali. Quando nos reunimos para pensar no próximo projeto, e compartilhamos desejos, vontades, inquietações, o Bom Retiro apareceu com muita força.
\end{abstract}

Por uma série de razões - históricas, econômicas, sociológicas, políticas, urbanísticas, demográficas -, o Bom Retiro é um espaço de características muito peculiares. Seu dado primeiro e mais fundamental é, sem dúvida, a multiplicidade de nacionalidades, etnias, religiões e culturas em sua composição:

(...)É um bairro que vem sendo ocupado por sucessivos grupos de imigrantes, desde sua formação. De 1870 a 1890, destacam-se os portugueses; de 1900 a 1940, os italianos predominam entre a população estrangeira; em torno dos anos de 1920 os judeus começaram a marcar presença; a partir dos anos de 1960 coreanos também começaram a chegar. Gregos, armênios e sírios também instalaram-se no bairro ao longo do século XX e, nas últimas duas décadas, bolivianos e peruanos e, mais recentemente, paraguaios, participam como moradores do bairro. ${ }^{2}$

As origens do Bom Retiro estão ligadas ao "cinturão de chácaras" que circundava o centro da cidade no século XIX (MANGILI, 2011). Os Campos do Guaré, como eram chamadas aquelas terras, abrigavam residências de fazendeiros e áreas de cultivo destinadas ao consumo próprio e ao abastecimento da cidade. A segunda metade do século viu o gradativo processo de urbanização da região. Em 1882, é instalado ali o primeiro alojamento para imigrantes em São Paulo, na Rua dos Imigrantes; em 1884, o grupo Prudente de Morais, primeira escola de ensino primário do município; em 1905, a Escola de Farmácia e em 1907 o Colégio Santa Inês.

Os primeiros arruamentos foram o início de um processo que ganharia força efetiva com a implantação da ferrovia, que rapidamente impulsionaria o loteamento das chácaras. O Bom Retiro era a porta de entrada dos imigrantes, que desembarcavam no porto de Santos e chegavam a São Paulo pela Estação da Luz. Não à toa, seria instalado ali, em 1893, o Desinfectório Central da cidade.

\footnotetext{
${ }^{2}$ FELDMAN, Sarah. Prefácio de MANGILI, Liziane Peres. Bom Retiro, bairro central de São Paulo - transformações e permanências 1930-54. São Paulo: Alameda Casa Editorial, 2011.
} 
Estes bairros que se estruturaram entre a linha férrea e o rio Tietê, e que podem ser caracterizados como bairros centrais industriais, surgem nesse contexto de uma primeira expansão urbana significativa da cidade, marcada pela dinâmica industrial e pela presença da população imigrante. Como afirma Fernandes, essa constituição inicial, cristalizada no espaço, vai dar o tom de sua própria evolução, uma vez que um espaço, uma vez constituído, assume formas de desenvolvimento com dimensões e tempos que, ainda que regidos por uma lógica geral, guardam movimentos próprios. ${ }^{3}$

O adensamento e a verticalização do bairro o fizeram muito populoso, sempre ligado a populações operárias pobres, vivendo e trabalhando em más condições. Desta forma a natureza do Bom Retiro foi se definindo:

Mas já no início do século XX o bairro do Bom Retiro seria marcado não pela presença de grandes indústrias, e sim daquelas com caráter artesanal. O censo de 1920 revela a presença de 75 fábricas no bairro, e de 252 "casas de negócios". Tratava-se de pequenas indústrias, muitas instaladas no mesmo espaço ou espaço adjunto à moradia, não raro em telheiros no fundo do quintal, onde trabalhavam membros da própria família ou alguns poucos funcionários, moradores do próprio bairro. Essa seria a característica industrial predominante na cidade na primeira metade do século XX, e marcaria a paisagem dos bairros centrais: a de serem bairros industriais, sem grandes evidências de indústrias no seu território." ${ }^{4}$

Há nesta análise uma dualidade essencial na constituição do Bom Retiro e que é fundamental à compreensão da peça. É esta invisibilidade pulsante do trabalho o bairro "industrial" sem "grandes evidências de indústrias". Assim nasceu o bairro e assim ele é até hoje, com as tecelagens ocultas pelo deserto de suas ruas, pela indiferenciação de suas fachadas de janelas cerradas.

"Bom Retiro, 958 Metros" não é um espetáculo em que se acompanha uma história, mas sim muitas. A estrutura dramatúrgica e os procedimentos de encenação fazem com que ele transcenda uma unilateralidade do discurso e se assemelhe, em muitos sentidos, a uma instalação, um discurso múltiplo e de virtualmente infinitas possibilidades de fruição próximo das artes plásticas. É como se a peça operasse nos moldes de uma grande instalação cênica, na qual se pode entrar e olhar por muitos lados - ainda que, o tempo todo, seja teatro: atores falando e agindo, recursos de encenação, uso de luz, som e música, personagens, narrativa etc.

\footnotetext{
${ }^{3}$ MANGILI, Liziane Peres. Bom Retiro, bairro central de São Paulo - transformações e permanências 1930-54. São Paulo: Alameda Casa Editorial, 2011.

${ }^{4}$ Idem.
} 
Só que essa condição de total liberdade como espectador nos é subtraída de tempos em tempos, e nos vemos gradualmente reinseridos em algo que conseguimos identificar e aproximar ao que estamos habituados a reconhecer como um espetáculo teatral.

Há um jogo constante entre o interno e o externo, o aberto e o fechado, o público e o privado. Nós, enquanto espectadores, somos levados o tempo todo a questionar esta própria condição. No shopping center, no início da peça, a relação é marcada por certo equilíbrio: há um discurso único, direcional, que me leva a cumprir determinado percurso; a cena "briga" com lojas fechadas, o reverso de um ambiente que estamos acostumados a frequentar.

Quando o espetáculo ganha a rua, a relação é subvertida. A liberdade do espectador é total, e a cena vai para o que Araújo e a atriz Luciana Schwinden definiram como a "luta" com a rua. E de fato a rua é absolutamente fascinante, viva. Neste trecho do espetáculo fica evidente a força do teatro criado pelo Vertigem e sua rara capacidade de criar imagens poderosas.

Por fim, no momento em que descemos às entranhas do Taib, nossa condição de espectador é levada ao terreno mais palatável ao senso comum: nos sentamos nas poltronas de um teatro. Se na rua tínhamos total liberdade para dirigirmos nosso olhar (e nosso próprio corpo) para onde quiséssemos, aqui, estamos de volta a uma sala escura, com seu palco italiano e suas poltronas de couro vermelho.

Mas que teatro é esse? Um espaço em ruínas, de um tempo em ruínas. Descemos ao inferno do consumo, das drogas, do mundo doente e desumano em que vivemos. Quando somos rigorosamente espectadores de uma peça de teatro, o somos nas ruínas de um espaço (um dos últimos em que as palavras talvez ainda façam algum sentido, nos diz a atriz) que representou a utopia de muita gente - a Casa do Povo, erguida por judeus comunistas e de fundamental importância na memória afetiva dos moradores do bairro.

Em “Bom Retiro, 958 Metros” os personagens estão à procura de alguma coisa: um vestido, uma pedra de crack, um emprego. Seres frustrados, obstinados em uma busca incessante que se consome em si mesma.

A chave de interpretação impressa pelos atores oscila entre um realismo estrito e algo de opaco, fugaz, fantasmagórico. A consumidora é um personagem que evidencia bem essa questão. Em sua "queda", na busca delirante pelo vestido vermelho, ela passa 
de alguém identificável como próximo para um ser esvaziado, sem alma, que se devorou em sua obsessão pelo vestido. De certa forma, todos aqueles personagens são como espectros que vagam em uma cidade às avessas, em buscas cegas. As repetições do texto nos envolvem em uma espiral, como que sufocando aqueles fantasmas.

Nesse ponto, parece oportuno recorrer às considerações da professora Olgária Matos, em palestra sobre Walter Benjamin:

\begin{abstract}
A falsa consciência significa uma ação que realizamos conscientemente, mas com falsa consciência. Não conhecemos as motivações e o sentido último das escolhas, porque consumimos aquilo de que não necessitamos, e necessitamos daquilo que não consumimos. Isso pode ser ampliado para o fenômeno do fetichismo, quando Adorno diz que "os indivíduos não são mais agentes do seu destino, pois quanto mais os indivíduos se veem transformados em coisas, mais investem nas coisas com uma aura humana". As "mercadorias visuais" produzem imagens fantasmas, elas são uma espécie de sonho em estado de vigília que confere ao nosso tempo esse caráter onírico, segundo Benjamin. (...)

Segundo Sloterdijk, "a interpretação que Benjamin dava das passagens, se inspirava na ideia marxista realista, embora trivial, segundo a qual, por detrás das superfícies brilhantes das mercadorias, dissimula-se um mundo de trabalho desagradável, e, por vezes, sinistro. O contexto mundial criado pelo capitalismo era, enquanto tal, um inferno. O belo mundo sobre o vidro era um dos avatares do inferno de Dante". ${ }^{5}$
\end{abstract}

Em certo ponto da entrevista, Araújo evocou com alguma relutância o termo "colcha de retalhos", com justo receio de que isso pudesse sugerir confusões acerca do espetáculo; de fato, na maioria das vezes em que este termo é empregado, o que vemos são painéis de fragmentos de memórias, evocações nostálgicas e memorialismos de toda sorte - definitivamente, não o caso deste espetáculo. A metáfora, por sua vez, talvez seja mais feliz do que se supunha inicialmente. Mais do que nos mostrar estes retalhos do qual o espetáculo é composto, ele nos faz pensar também sobre as linhas que costuram esses retalhos. Afinal, o que une aquelas personagens, neste mundo dominado pelo consumo, em que o mercado institucionalizado domina e determina as relações sociais? A rádio, neste aspecto, aparece como um interessante fio a unir esses fragmentos de personagens e histórias. Mais do que uma solução dramatúrgica para "amarrar" as cenas e direcionar o público, ela problematiza e questiona os assuntos tratados em cena.

Quando pensamos na consumidora obsessiva atrás de um vestido vermelho, que sempre encontra a loja fechada, ela aparece tão próxima daquele viciado em crack que discute com sua pedra. Em seus discursos delirantes, ambos pendulam entre ocasionais

\footnotetext{
${ }^{5}$ MATOS, Olgária. "Fetichismo: princípio de realidade e 'morada do sonho'” São Paulo, 9/6/2007.
} 
laivos de lucidez e um mar de incongruências, um discurso vazio, produto de um mundo fraturado e doente. Gente que é o resíduo produzido por essa máquina que consome pessoas em nome de dinheiro. Ou então as duas realidades tão distintas vividas por essa consumidora e a imigrante clandestina boliviana que costurou esse próprio vestido cegamente desejado pela primeira, unidas neste mesmo espaço. Enquanto uma vaga pelas ruas à noite imprecando contra os muros e desejando que suas palavras sejam pedras a estilhaçar vitrines, a outra trabalha sem descanso para enriquecer quem lhe explora.

A estes espectros vagantes nós, público, nos unimos na descida a este inferno urbano do trabalho, da exploração, do vício, do desamparo, da falência do estado e das instituições. Vagamos por aquelas ruas desertas, e também nos tornamos parte desses seres fantasmagóricos.

O fato de estarmos caminhando por aquelas ruas, à noite, descobrindo ângulos de uma São Paulo até então "invisível" já é um ato de reivindicação e retomada da cidade. Mas é só prestar um pouco de atenção para constatar o quão visível é o peso do trabalho e do dinheiro naquele lugar. Uma opressão que age pela inação. É no silêncio e no deserto das ruas que se faz presente o peso de todo o complexo sistema que une aquele viciado em crack, aquela consumidora, aquela manequim defeituosa, o bizarro desfile de moda, o Taib em ruínas. É a invisibilidade pulsante do trabalho a que nos referimos anteriormente.

Tornam-se reveladores, nesta perspectiva, os dados recolhidos nos censos do IBGE. Em 2008, o Bom Retiro tinha 21.707 habitantes. Quase cinquenta anos antes, em 1960, eram 53.893 os moradores do bairro. Esta cifra, tão expressiva, só vem reforçar esta sensação de êxodo, de amplos vazios - a própria caminhada que o público faz antes do início da peça propriamente dita (há quem afirme que o espetáculo já começa neste momento), da Oswald à porta do shopping na Rua Cesare Lombroso, mostra este Bom Retiro deserto. Este cenário, porém, é da porta pra fora. Em muitos daqueles prédios fechados há tecelagens onde as costureiras estão trabalhando.

O cortejo, guiado por um sistema de som, projeções e iluminação operado por um eficiente time de contrarregras, invariavelmente impressiona aqueles que cruzam seu caminho; exceção feita a um ou outro morador que, distante, acompanha a passagem pela janela. Há algo de expressionista, talvez de surrealista, na experiência toda. Ao instaurar-se na rua, o espetáculo também dialoga com esse espectador acidental que, por estar passando naquela hora e naquele lugar, capta apenas uma cena, ou um par 
delas. Ou também com aqueles que efetivamente resolvem acompanhar o espetáculo. E quando se estabelece esse contato, mesmo que breve, está colocada uma via de mão dupla (ou múltipla, já que são muitos os elementos que impactam e são impactados por estes fatores externos: atores, técnica, público...) entre a peça e este espectador. A cidade e a obra interferem uma na outra, e deste atrito se faz o espetáculo.

Se atravessamos o que representa estar na rua e nos detemos sobre como esta inserção se dá, nos damos conta de como o trabalho do Vertigem parece desmontar falsas dicotomias que, pela força da inércia, se cristalizam e acabam por ter grande poder. "Bom Retiro, 958 Metros" é uma proeza técnica e logística. Tanto em termos de planejamento e concepção como na execução, o espetáculo ganha vida por meio de um complexo, muito bem coordenado e quase megalomaníaco (no melhor dos sentidos) trabalho de equipe.

Mas é preciso que isso esteja a serviço de algo, de outro modo seria puro fetichismo artístico, egolatria, exercício vazio para demonstração de técnica. $\mathrm{E} o$ Vertigem, em sua busca por um teatro que verdadeiramente surja da cidade e interfira nela, consegue atingir uma relação orgânica, fluida, entre essa complexa engenharia e a cena. Ao lado de todo o edifício tecnológico e técnico está um teatro que faz uso de suas técnicas mais essenciais. Os recursos para atrair a atenção do público para determinado ponto e permitir que atores passem para outro ponto sem serem vistos são um exemplo de como o Vertigem se ampara nestes pólos falsamente opostos para construir seu teatro. É como conta Schwinden:

Há caminhos que o público não vê. A gente entra em ruas que as pessoas não acompanham. Eu atravesso uma galeria que liga a Rua Aimorés à José Paulino para chegar lá no desfile antes do público... Onde fica a coxia do ator num espetáculo como esse? É nos cantos, nas ruas, numa fachada de loja, atrás de um tapume, de uma caçamba, de um carro... Muitas vezes me troquei atrás de um carro, tem uma árvore. Isso é fascinante, e muito novo pra gente. E eu acho que esse é o jogo, é a parte que eu mais gosto. E nós somos muito respeitosos com isso, com a rua. Porque ela é o nosso palco e a nossa coxia....

Nas palavras dos integrantes entrevistados, a peça aparece como um forte desejo de continuidade do grupo, um momento de revisão de afinidades artísticas, em meio à chegada de toda uma nova geração de jovens integrantes. Recolhidos os cacos após 
uma experiência traumática, quando da montagem de "BR-3", o Vertigem reencontra uma potência criativa e discursiva que tanto Ihe foi reconhecida em trabalhos passados.

É impossível, à luz de seu processo de criação, dissociar os resultados cênicos obtidos pelo grupo de seus modos de produção. É um teatro que se faz verdadeiramente coletivo, em todas as suas partes constitutivas. É absolutamente coletivo na concepção e criação. É, e tem que ser, necessariamente coletivo em sua execução, demandando um alto grau de entrega de seus integrantes. E também é essencialmente coletivo em sua fruição, dando ao público - e à própria rua - um papel de vital importância no estabelecimento da própria existência da obra de arte, naquele momento, naquele lugar.

Em um mundo cada vez mais impessoal, consumista e individualista, o teatro é um dos poucos espaços possíveis em que o outro e nossa relação com ele são o centro, a base fundamental, a própria razão de ser. E "Bom Retiro, 958 Metros" avança as fronteiras dessa relação. No fundo, o espetáculo é um grande exercício de pensar e sentir coletivamente. Ao questionar a cidade e as condições de vida dos que nela vivem, o Vertigem repensa o próprio teatro e a arte enquanto possibilidade de resistência. 